\title{
Cardiac Valve Injury
}

National Cancer Institute

\section{Source}

National Cancer Institute. Cardiac Valve Injury. NCI Thesaurus. Code C100069.

An event causes abnormal valve function; this is usually a tear in leaflet or chordae tendinae and manifests as a new regurgitant. (ACC) 